\title{
Differentiation of Social Roles and Life Domains as Predictor and Promoter of Flourishing
}

\author{
Margarita Bakracheva \\ Sofia University St. Kliment Ohridski, Sofia, Bulgaria \\ Email:m.bakracheva@abv.bg
}

How to cite this paper: Bakracheva, M. (2019). Differentiation of Social Roles and Life Domains as Predictor and Promoter of Flourishing. Psychology, 10, 1188-1216. https://doi.org/10.4236/psych.2019.108077

Received: May 21, 2019

Accepted: June 27, 2019

Published: June 30, 2019

Copyright $\odot 2019$ by author(s) and Scientific Research Publishing Inc. This work is licensed under the Creative Commons Attribution International License (CC BY 4.0).

http://creativecommons.org/licenses/by/4.0/

\section{c) (i) Open Access}

\begin{abstract}
The article outlines the predicting effects of the self-congruence, attachment, stress, anxiety, depression, and happiness, on flourishing. The differentiation of social roles and life domains is included as a supposed pathway to flourishing and well-being promotion. 359 volunteers completed self-congruence, stress, anxiety and depression, relationships, happiness, differentiation and flourishing self-reporting scales and incomplete sentences on the daily way they differentiate their life domains and social roles as a form of preventive and proactive coping. In the hierarchical model, the accounted flourishing dispersion is $84 \%$ with predictors' differentiation, happiness, low depression and relationships avoidance. In addition, the main effect of differentiation on both flourishing and all its predictors is reported. This leads to the conclusion on the importance of interventions to equip individuals with good differentiation abilities throughout life cycle.
\end{abstract}

\section{Keywords}

Flourishing, Happiness, Self-Congruence, Well-Being

\section{Introduction}

The pressure to achieving success along with the dynamic social and economic changes during the last decades, transform the developmental path of young adults and the life-long developmental path in adulthood. One of the implications is clearly expressed in the theory of emerging adulthood (Arnett, 2000). Emerging adulthood lasts until 29 years of age; this period is necessitated by the numerous alternatives and choices young people have to explore prior to make their stable commitments. Furthermore, this exerts effect on the other age groups as well, and changes the perspective of construing the real and ideal selves. Flourishing is considered to be a measure of self-realization and self-actua- 
lization; the state of highest happiness and eudaimonic peak of the well-being, comprising social relations, goals and environmental mastery. Our interest is twofold: 1) to study the relations among self-congruence, attachment, experienced stress, anxiety, depression, happiness, and flourishing; 2) to test the social roles and life domains differentiation as a suggested predictor of flourishing in a sample of emerging adults and adults. We consider differentiation adaptive self-reflection and specific proactive coping that can promote happiness and flourishing.

We would like to note a specificity of well-being in Bulgaria. In cross-cultural comparisons Bulgarians usually have lowest levels of well-being and happiness, but there are countries of lower individualism, GDP and democracy as main predictors of well-being. To explore the underlying reason, we made a series of studies during the past two decades. The summarized quantitative result for these years is that about $70 \%$ of Bulgarians report to be dissatisfied with their life, but about $70 \%$ of them are happy. This is a contradiction only at first glance and the explanation is in the qualitative results-what people declare to make them happy and satisfied with life. Happiness is associated mostly with inner states-love, health, quality relations and a wide range of feelings and emotions, without any link to the material world. Life satisfaction and well-being on their part, are also associated with relations, however to a great extent with all life domains-employment, house, personal belongings, income, etc. In other words, the semantic fields of happiness and life satisfaction are quite different and Bulgarians make a clear demarcation between their experiences and the living environment. Happiness and life satisfaction are linked one to the other, but follow different paths of pursuing and maintaining (Bakracheva, 2009; Bakalova et al., 2015). Furthermore, the social self-representations of Bulgarians are self-discriminatory to a large extent (Manolov, 2019) and this has effect on self-concept construing.

\section{Theoretical Framework}

There are numerous classifications and concepts of self and self-congruence, stressing on the developmental self-construal path. The common in them is that self-representations are viewed not as static, but from the viewpoint of their congruence or discrepancy. The classic theories conceptualize self with two dimensions: ideal and real (James, 1890). In the humanistic perspective the self comprises self-image, ideal-self and self-worth. The precondition for fulfilment of the individual strive after self-actualization is the congruence of the self-image that is close to the ideal self (Rogers, 1961). Psychoanalytical theories stress that the incongruence of self-perceptions vs. the healthy self-image leads to neuroticism (Freud, 1957; Horney, 1950; Reich, 1954). In the self-discrepancy theory are differentiated actual self (how person perceives herself), ideal self (how person would like to be) and ought self (person's ideas about how she should be). Discrepancies between the different domains of the self affect the emotional well-being and the overall levels of happiness, social integration, self-esteem and 
life-satisfaction (Higgins et al., 1985; Higgins, 1987). Further extension is given with inclusion of the negative self-developmental path-the key motivation for development is considered the opposite of the undesired self-the not me and the bad me. Individuals are led by the idea what they do not want to be rather than by what they want to be, or in other words, the dominating is the negative choice-the tyranny of the should and should not underlies the ideal self (Ogilvie, 1987). This negative self-construal is supported also by the feared self-the fear of possible becoming a person someone does not want to be (Carver et al., 1999).

The term virtual self has already been used by many researchers (Bessière et al., 2007; Yee et al., 2009; Behm-Morawitz, 2013; Suh, 2013). In the new reality the virtual self implicates thealready inherently linked real and virtual life. In this line are the results of a study, revealing that players tend to regard their virtual selves as inseparable from their everyday lives (Crowe, 2010). We consider virtual identity as a domain of the psychosocial identity, which can promote attainment of commitments and exploration or impede them depending on the individual situation. However, in any case, virtual life today cannot be separated from the real life regardless the age and behaviour of the e-consumer (ref. Bakracheva \& Bakalova, 2011).

The positive implications reported are that the virtual self might facilitate exploration of the ideal aspects of the self, lessen the perceived self-discrepancy and thus promote the emotional well-being (Behm-Morawitz, 2013). Online environment and social platforms provide users alternatives to choose what to disclose to the others (Walther, 2007) and environment to express aspects of their ideal self (Manago et al., 2008). Indirectly this has effect on construal of the personal and social identity (Spies Shapiro \& Margolin, 2014). Regardless the age,the social networks are an easy way for experimentation with different selves and creation of ideal self (Zhao et al., 2008) and ought self in response to the perceived social norms (Manago et al., 2008; Back et al., 2010). Furthermore, this process extends and expands the initial commitments and choices in childhood and adolescence and proceeds with reorganization of the identity in adulthood. Virtual identity model in adulthood replicates the identity construal model-adults in the same way as adolescents most of all need positive feedback from others and do not differentiate their life online and offline, but consider them to be one. They explore the alternatives and search for commitments in virtual reality (Bakracheva et al., 2014).

The conclusion of researchers is that social networks provide benefits and positive emotions ( $\mathrm{Lin} \& \mathrm{Utz}, 2015$ ), however, depending on the individual situation, they can have detrimental effects (Brooks, 2015) and become addictive (Rosen et al., 2013; Fox \& Moreland, 2015). Negative effects are accounted for individuals with personal deficits, e.g. low self-esteem, life satisfaction, etc., which can result in preoccupation up to a level of addiction (Turel \& Serenko, 2012; Brand et al., 2014; Turel et al., 2014). The negative aspect of virtual identity 
is related to individual dispositions and extreme compensation, specific for the non-mature identity and obvious in the fake identities (Haferkamp et al., 2012). False self-presentation is not a new phenomenon, however digital technologies provide an easy and fast way for this and thus the prevalence of fake identities and self-representations today is unprecedented. For a Bulgarian sample we have established for instance a lot of people, having only a fake profile in Facebook. The reasons, underlying this choice, are in three directions: fear from understanding their preferences if they declare them in an open manner; starting and maintaining "safe" love affairs; control on the life of real, former, or desired partner. In one of the experiments we created a fake profile with just a portrait profile photo and very scarce personal information. This profile had no posting and sharing activity and had not sent any invitations. However, just in one month (especially during the first week) the fake profile received more than 300 invitations for friendships and a lot of personal messages with self-disclosures, some of which containing very personal facts (Bakracheva, 2016).

Low degrees of falseness are natural and not harmful. On the contrary, high degrees of falseness in long-term, resulting from persistent gaps between the true/real self and the false/ideal self can become pathological (Rogers, 1959). For virtual self the difference between the real and the virtual self is supposed to be bigger when an individual is not satisfied with his or her real life and consciously or unconsciously creates an alternative environment to compensate real-life deficiencies. We can conclude that temporary rewards and benefits can promote self-congruence and development. This behaviour can be considered positive, if it is for a short period as a coping strategy. However, excessive and fixed use of this specific coping may result in persistent addictive passive coping and prevent development.

Attachment styles are based on the classic theory about formation of attachment in new-borns and children that later predicts the attachment and psychological intimacy with others in adulthood (Bowlby, 1969; Ainsworth et al., 1978). The assumption is that the emotional bonds with mother and parents are replicated in all emotional relationships and intimacy with significant others. Bartholomew \& Horowitz (1991) differentiate four styles, depending on the relationships avoidance and anxiety degree (low vs. high) and the mode of perception of self and others: one secure and three insecure-preoccupied, fearful-avoidant, and dismissive-avoidant. Secure attachment is described by low dependence and low avoidance and describes individuals with attained intimacy and autonomy. Preoccupied individuals have high dependence and low avoidance, i.e., they are preoccupied with relationships. Dismissive individuals experience high avoidance and low dependence-they are dismissing intimacy. Fearful individuals are high both on dependency and avoidance-they are fearful of intimacy and socially avoidant. The key role of secure attachment is reported in a number of empirical data, reporting that securely attached people tend to function better in social interactions in various life domains compared to 
the insecurely attached (Cassidy \& Shaver, 1999; Rholes \& Simpson, 2004). In personal aspect secure attachment is related to better self-esteem and resilience (Bowlby, 1979). Securely attached individuals experience less anxiety in communication and are more independent compared to the insecurely attached (Robin et al., 2007). People with secure attachment experience less depression (Simpson \& Rholes, 2004), less anxiety (Strodl \& Noller, 2003), and maintain healthier self-concepts (Mikulincer, 1995).

Stress, anxiety and depression are among the most studied concepts in psychology. Stress is introduced in physiology and psychobiology (Selye, 1976) and later conceptualized within the psychology (Lazarus, 1966, 1991; Lazarus \& Folkman, 1984; Lazarus \& Folkman, 1984, 1986). Stress, or the announced decease predictor of $21^{\text {st }}$ century has drawn the attention first as the body response to external changes. In psychological aspect stress can be positive in low doses when successfully managed or negative if persistent and chronic. Selye (1976) reveals the effect of non-specifically caused changes that constitute specific response pattern. The stereotypical response pattern or the general adaptation syndrome initiates a three step process: initial shock phase and a subsequent counter-shock phase. For psychological stress the key concepts are appraisal of the situation, i.e., individuals' evaluation of the significance of what is happening for their well-being, and coping, i.e., individuals' efforts to manage the specific demands in thought and action. Lazarus' stress theory describes the stress as a transaction between the individual and the environment (Lazarus 1991). Several social and personal constructs have been proposed as stress buffers, e.g. social support (Schwarzer \& Leppin 1991), sense of coherence (Antonovsky, 1979), optimism (Scheier \& Carver, 1992). The conservation of resources theory postulates that stress occurs either when people experience loss of resources, when their resources are threatened, or when people invest their resources without subsequent gain. The general assumption is that individuals can learn how to keep and maintain their resources as to be well equipped to cope (Hobfoll et al. 1996). We suggest that coping can be regarded each behaviour that is either reactive, preventive or proactive (Bakracheva, 2017).

Anxiety is a personality trait. Most personality taxonomies situate it within the higher-order dimension of neuroticism (Eysenck, 1967), negative emotionality (Tellegen, 1982) or low emotional stability (Goldberg, 1992). Twin studies have confirmed that depression and anxiety share a genetically determined neurobiological component (Jardine et al., 1984; Roy-Byrne et al., 2002). Recent research distinguishes anxiety from fear (Cooper et al., 2007; Perkins et al., 2007). The tripartite model comprises depression, anxiety, and the underlying construct of both of them - the generalized distress (Clark \& Watson, 1991).

Depression is usually considered psychopathological disorder or temporary state. We are most interested in depression, experienced in relation to attachment and self-incongruence. Beck (1967) suggests that people who tend to show depression in adulthood are affected by their early relationship with their care- 
givers. In a lot of studies are confirmed the links with early infant-caregiver relationship and that the attachment and depression are connected (Kobak et al., 1991), whereas secure attachment is considered a specific buffer of depression (Mikulincer et al., 1993). On the contrary, insecure attachment styles are reported to be related to vulnerability to depression (Reinecke \& Rogers, 2001; Bifulco et al., 2002) and insecure subjects experience more depressive symptoms compared to the secure ones (Carnelley et al., 1994).

Eudaimonic well-being is related to the strive after revealing one's full potential, conceptualized in the classical theory of self-actualization (Maslow, 1954) as a natural and dynamic life-long process of growth with full concentration and absorption. Reiss \& Havercamp (2005) suggest that 36 years is the reasonable cut-point of the specific age for the attainment of self-actualization. The lifespan approach also considers middle age the period for effective self-reflection, re-assessment, and finding the balance between the intrinsic motivation and social norms (Huyck, 1993; Shek, 1996; Lachman, 2004). Concerning the emotional component of well-being happiness, contrary to the models suggesting a stable baseline, the sustainable happiness model postulates that personal chronic happiness level can be increased and sustained afterwards. One of the ways for this is the effective expression of the ideal-self, which continuously raises and maintains the sense of happiness (Sheldon \& Lyubomirsky, 2009; Lyubomirsky et al., 2005).

Flourishing is defined as high levels of both hedonic and eudaimonic wellbeing. Hedonic well-being comprises subjective or emotional well-being, comprising the components happiness, life-satisfaction and positive-negative affect balance (Diener, 1984). Psychological well-being and social well-being are part of the eudaimonic approach and include meaning, engagement, purpose in life, positive relations with others and personal growth (Keyes, 2002; Ryan et al., 2008; Ryff, 1989). Both hedonic and eudaimonic activities should be pursued for the most optimal and diverse well-being (Huta \& Ryan 2010). The two approaches to human flourishing in positive psychology are Keyes' (2002) mental health continuum and Seligman (2011) PERMA model. The common in both conceptions is that flourishing is the optimal human functioning, living life that is meaningful, with close relations with others, personal growth and resilience. Keyes describes flourishing as elevated levels of combined psychological, emotional, and social well-being and operationalizes it as a theory, comprising the three approaches: subjective well-being (Diener, 1984; Diener et al., 1999), psychological well-being (Ryff \& Keyes, 1995), and social well-being (Keyes, 2005, 2006, 2007). Seligman's model for human flourishing is based on his idea of authentic happiness (Seligman, 2002). Individuals are at their happiest (i.e. flourishing) when they are high on PERMA - the acronym for flourishing components-positive emotions, engagement, positive relationships, meaning and accomplishments (Seligman, 2011). To flourish means to experience self-fulfilment, accomplishment of meaningful goals and good connections with others (Selig- 
man, 2011). It reflects both the result, but also the continuous engagement in authentic behaviours. Flourishing is not fixed, but something that can be learnt and pursuit and the best is interventions, aimed at flourishing, to be implemented at an early stage in the individuals' development (Seligman, 2011). To summarize, both happiness and flourishing can be pursuit and modified.

\section{Current Study}

Our interest is in the effect of self-congruence, relationships avoidance and relationships anxiety, stress, anxiety, depression, and happiness on flourishing. In addition, we are challenged to trace the implications of differentiation of social roles and life domains, resulting from self-reflections and self-concepts as an important part of emotional intelligence. We do not consider the complex concept of emotional intelligence, as for us most important is its foundation-the ability for self-reflection and awareness, recognition and management of own emotions and states. This study comprises 16 variables (Table 1).

Alignment of selves facilitates self-actualization and enables individuals' to fulfil their potentials (Rogers, 1961), and thus to flourish. In line with the negative path of self-construal-what a person perceives should not and does not want to be-is considered stronger compared to what the individual wants to be and the pressure of should. In a student sample is replicated that actual-undesired self-discrepancy has a stronger association with depression than actual-ideal self-discrepancy (Cheung, 1997). For this reason we include what we consider indirect result nowadays-the implication of all shoulds and oughts in the virtual self. Virtual self as the easiest self-representation, giving a wide range of alternatives for experimentation and exploration. Our concept of virtual self is that it performs as a daily coping strategy. The virtual identity can compensate or promote the real flexible mature identity. What happens virtually is adaptive

Table 1. List of study variables.

\begin{tabular}{c} 
ideal-real self-congruence \\
real-virtual self-congruence \\
ideal-virtual self-congruence \\
relationships anxiety \\
relationships avoidance \\
stress \\
anxiety \\
depression \\
differentiation \\
happiness \\
flourishing \\
sex \\
age \\
occupation \\
incomes \\
family status \\
\hline
\end{tabular}


for the particular period. We consider virtual self as a modern broad ought self, interrelated with the ideal self. We include as measures the overlapping between real and ideal self, real and virtual self and ideal and virtual self.

With regard to the relationship between attachment and self-discrepancy, secure attachment style is reported to lead to harmonized and consistent self, while insecure attachment style causes inconsistencies in the self (Mikulincer, 1995). The common in the theories is that experienced conflicts and incongruence of self-perceptions result in negative emotions, frustration, guilt, embarrassment, anger and anxiety. Thus, we include relationships avoidance and anxiety, selfcongruence, stress, anxiety, and depression.

A large body of research reveals that sex, higher income, higher education, living with a partner and good employment are positively related to subjective well-being (Diener et al., 1995, 1999; Diener \& Ryan, 2009; Veenhoven, 1996, 2008) and psychological well-being (Ryff \& Keyes, 1995; Ryff \& Singer, 2008). Males, adults between 45 and 54 years, adults with more years of education and married, are most likely to flourish (Keyes, 2002; Keyes, et al., 2002; Keyes \& Simoes, 2012). We include sex, age, occupation, family status and subjective assessment of incomes.

We include also the subjective report of perceived happiness as a specific measure, in particular for the situation in Bulgaria. In cross-cultural comparisons Bulgarians are reported to be the unhappiest nation, however in national research the situation is different due to the strong differentiation in replies (free associations) what makes people feel happy and satisfied with their life. The role of differentiation is reported as significant-when participants rate themselves in general and in respect to distinct roles (student, employee, child, friend and romantic partner), they give different replies-authenticity scores are positively correlated with satisfaction within the different roles (Sheldon et al., 1997).

This study aims to examine the relationships among self-congruence, differentiation of social roles and life domains, relationships avoidance and relationships anxiety, stress, anxiety, depression, happiness, and flourishing (Figure 1). We expect that 1) self-congruence, low depression, stress and anxiety and low relationships avoidance and relationships anxiety along with happiness will predict flourishing; 2) good differentiation abilities will promote flourishing and happiness and furthermore, predict better self-congruence, lower levels of stress, anxiety, depression, and secure attachment.

\subsection{Measures}

Selves overlapping - we made an adaptation of the Inclusion of Other in the Self (IOS) Scale (Aron et al., 1992). We kept the instruction: Please, circle the below picture that best describes your relationship. Instead of self-other and selfcommunity as in the original, we include real-ideal self, real-virtual self and ideal-virtual self (below is example for real-ideal). We shortened also the self- 
reporting scale from 7 to 5-point-large distance, no overlap, close one to the other, some overlap and most overlap.
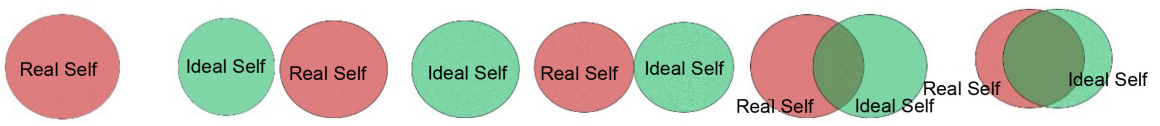

\subsection{Differentiation of Social Roles and Life Domains}

We used a 15-items self-report scale we have designed to measure the self-reflections and abilities of people to differentiate personal and professional life and various life domains in view to maintain different self-perceptions, self-esteems and shift from one life domain to another. The social roles included are professional, friend, partner, child, parent, and person in general. Exemplary items "In my job I am aware of my advantages and disadvantages and feel OK with them", "It is easy for me to differentiate professional and private life and keep the balance", "I have friends for my different interests-with some I just amuse, with others go to theatre and discuss performances afterwards, others for sports", "I have different friends to share different issues with", "I don't expect my partner to share all my interests", "I have no problem to be alone-I am never bored", "I recognize most of my emotions and am completely aware how to manage them", "I have a lot of hobbies or activities that are interesting for me". The 15 items are selected out of a pool of 35 initially included based on factor and reliability analysis of the piloted scale. The self-reporting scale has 3 positions: agree, neither agree, nor disagree, disagree. The second part includes completion of 25 incomplete sentences-examples: "When I appraise myself, I usually think about...", "When I have to reply to the question Who am I, I usually include...", "When it comes to my ideal self, I strive after...", "In social networks I usually...", "In social networks I follow...", "My friends in SN are...", "The pages I follow in SN are...", "I usually smile daily...".

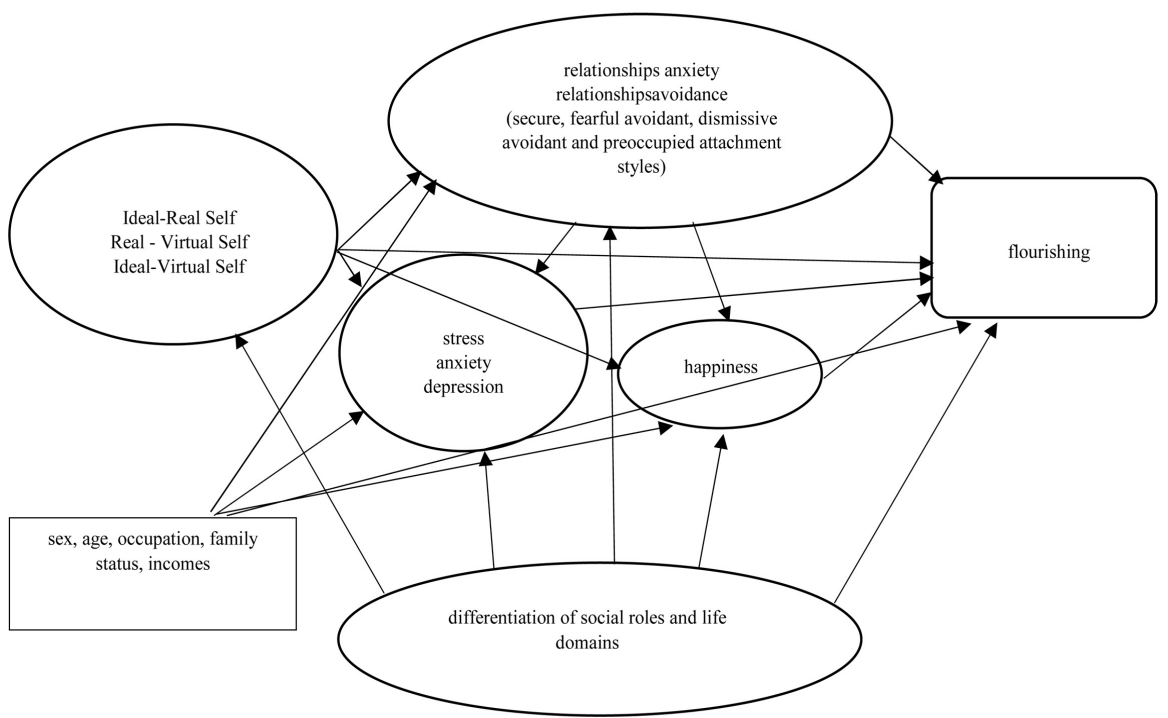

Figure 1. Model of studied variables and supposed effects. 
Principal component analysis extracted three components-personal relations, professional life and time framed presence of meaning, explaining 37\%, $22 \%$ and $15 \%$ of the variance respectively. The answers scale is 3-point: agree; neither agree nor disagree; disagree. The three positions of the self-report scale are selected in view to facilitate experts' coding of the incomplete sentences. Completed sentences had been assigned by three experts to the summarized codes of good/moderate/low differentiation, supplementing the items scale.The agreement of experts' assessments is $81 \%$.

Experiences in Close Relationships Questionnaire-Revised (ECR-R) (Fraley et al., 2000). ECR-R self-report inventory categorizing subjects in four groups: secure (low avoidance and anxiety), dismissing (low anxiety and high avoidance), preoccupied (low avoidance and high anxiety), and fearful (high anxiety and avoidance). The original version comprises 9 items, used to assess attachment with respect to four target figures (mother, father, romantic partner, and best friend). We used the short version of 9 items, describing the general attachment style and 5-point Likert-response scale: strongly agree, agree; neither agree nor disagree; disagree; strongly disagree.

DASS-21 scale (Lovibond \& Lovibond, 1995). The scale is 21 -itemed, 7 items measuring each of stress, anxiety and depression. The depression scale assesses dysphoria, hopelessness, devaluation of life, self-deprecation, lack of interest/involvement, anhedonia and inertia. The anxiety scale assesses autonomic arousal, physical effects, situational anxiety, and subjective experience of anxious affect. The stress scale is sensitive to levels of chronic non-specific arousal. It assesses difficulty relaxing, nervous arousal, and being easily upset/agitated, irritable/over-reactive and impatient. The Likert-response scale is 5-point (modified with added middle point): did not apply to me at all; applied to me to some degree, or some of the time; cannot determine, applied to me to a considerable degree or a good part of time; applied to me very much or most of the time. We modified also the instruction each statement to be measured for the period of preceding month not the preceding week as in the original.

The happiness self-report scale includes 5 -items with 5 response options: very happy, happy, neither happy, nor unhappy, unhappy and very unhappy, and comprises items for assessment of life in general, during the last year, during the last week, in comparison with friends, and in comparison with virtual friends. The scale is based on our previous studies and most of the research on happiness, accounting for subjective experience in general and narrower time limits and in comparison with others. The period of assessment of experienced happiness, as well as the reference framework-replies in comparison with others-produce different scores, thus we included these two perspectives. The possible range of scores is from 5 (lowest possible) to 25 (highest happiness possible).

The Flourishing Scale (Diener et al., 2009)-a brief 8-item summary measure of the respondent's self-perceived success in key domains such as relationships, 
self-esteem, purpose, and optimism. The scale provides a single psychological well-being score. We modified only the Likert response scale from 7 to 5 -point (without slightly agree/disagree: strongly agree, agree; neither agree nor disagree; disagree; strongly disagree). The possible range of scores is from 8 (lowest possible) to 40 (highest PWB possible). A high score represents a person with many psychological resources and strengths.

\subsection{Participants}

The convenience sample comprises 359 participants, enrolled in master programmes in humanities and social sciences-33\% males, $67 \%$ women; $50 \%$ below 25 years of age, $22 \%$ aged 25 - 35 years and $28 \%$ above 35 years of age. $46 \%$ of the volunteers currently only study, $54 \%$ work and study. $18 \%$ out of them are married, $37 \%$ live in cohabitation and the remaining $45 \%$ are single. Concerning their subjective assessment of individual incomes $23 \%$ report their incomes are below the average; $67 \%$ report their incomes are the average and $10 \%$ consider their incomes are higher than the average. The volunteers were recruited from master programmes only in view to include both emerging adults and adults. Furthermore, this gives option to include both employed and unemployed subjects with different family and economic status and in this way to have a more heterogeneous sample, age-specific in view to self-awareness and flourishing.

Data were collected in March-April 2019. The received complete answers were from distributed 500 paper-and-pencil forms. A cross-sectional predictive research design was carried out. Data were analysed by reliability analyses, descriptive statistics, ANOVA, and linear and multiple regression analyses (IBM SPSS Statistics 25).

\section{Data Analysis}

In this section we will present first the general distribution of the self-congruence (4.1), attachment styles, and differentiation in percent, the descriptive statistics (4.2), the demographic variables effect on all variables (4.3, the effect of self-congruence (4.4) and attachment (4.5) on flourishing and other variables, correlation among the variables (4.6), and regression analysis results for flourishing predictors (4.7).

\subsection{Description of Selves Overlapping, Attachment Styles, and Differentiation}

For the selves overlapping the results reveal that highest is the percent of reported overlapping and closeness, which is indicative for the self-reflection and objective reporting. Most overlapping and no overlap follow next, and least are the reported great distance in selves. The descriptive cross-tabulation in Table 2 confirms that this distribution of overlapping is related to the distribution in cells for the overlapping between ideal and virtual self and real and virtual self. 
Attachment styles in percent are almost equally distributed with leading dismissing avoidant $31 \%$, followed by secure $24 \%$, fearful avoidant $23 \%$, and preoccupied $22 \%$. In respect to differentiation it was accounted that $52 \%$ of the participants are high on differentiation, $20 \%$ have medium differentiation of social roles and life domains and $28 \%$ are low on differentiation or have not enough skills to differentiate the social roles and self-perceptions in various life domains.

\subsection{Descriptive Statistics}

Variables are normally distributed. In Table 3 are shown the descriptive statistics and the reliability of the scales.

The general results reveal that for all selves there is more than closeness one to the other. Non-statistically significant higher is the overlapping of real-virtual self (3.54), followed by real-ideal self (3.35) and lowest the ideal-virtual self (3.15). Difference in means is accounted solely between real-virtual (mean 3.54) and ideal-virtual (mean 3.15) selves $(\mathrm{t}=3421 ; p<0.001)$. Real-virtual self has more overlapping compared to ideal-virtual. The only significant difference is for real and ideal selves that have stronger congruence compared to ideal and virtual selves.

Table 2. Cross-tabulation of selves overlapping (in \%).

\begin{tabular}{cccc}
\hline & real-ideal self & real-virtual self & ideal-virtual self \\
\hline great distance & 4 & 9 & 9 \\
no overlap & 16 & 13 & 20 \\
close one to the other & 31 & 20 & 32 \\
some overlap & 38 & 33 & 11 \\
most overlap & 11 & 25 &
\end{tabular}

Table 3. Descriptive statistics of the variables.

\begin{tabular}{cccccc}
\hline & Minimum & Maximum & Mean & Std. Deviation & $\begin{array}{c}\text { Cronbach's } \\
\text { alpha }\end{array}$ \\
\hline Real-ideal self & 1.00 & 5.00 & 3.35 & 1.00 & \\
Real-virtual self & 1.00 & 5.00 & 3.54 & 1.23 & 0.60 \\
Ideal-virtual self & 1.00 & 5.00 & 3.15 & 1.14 & 0.76 \\
Relationships avoidance & 1.17 & 5.00 & 3.06 & 0.71 & 0.81 \\
Relationships anxiety & 1.00 & 5.00 & 2.55 & 1.12 & 0.88 \\
Stress & 1.00 & 5.00 & 2.76 & 0.85 & 0.98 \\
Anxiety & 1.00 & 4.71 & 2.18 & 0.89 & 0.89 \\
Deression & 1.00 & 4.71 & 1.80 & 0.89 & 0.89 \\
Happiness & 1.00 & 5.00 & 3.94 & 0.78 & 0.77 \\
Flourishing & 1.63 & 5.00 & 3.87 & 2.24 & 0.86 \\
Differentiation & 1.00 & 3.00 & & &
\end{tabular}


Attachment scales range from 1 to 5 , whereas relationships avoidance mean is in the middle (3.06) and relationships anxiety below the middle point (2.55). For stress, anxiety and depression the scale 1 - 5 reveals that all variables are below the middle point-means of stress is 2.76 , anxiety 2.18 and of depression 1.80 . Happiness in general is higher (4.02) compared to happiness with comparison to virtual friends $(3.85)(\mathrm{F}=72.729 ; p<0.007)$. Both happiness and flourishing mean scores are above the middle point (3.94 and 3.87). Except for relational avoidance, all scales have good reliability. It has to be noted that stress, anxiety, and especially depression, have means below the middle point of the scales, but happiness and flourishing-above the middle point.

\subsection{Effects of Sex, Age, Occupation, Family Status, and Income}

Sex, family status, incomes and occupation have no effect on the relationships avoidance and anxiety. Age has slight effect on anxiety-the group below 25 years compared to the group above 35 years of age $(\mathrm{F}=2934 ; p<0.057$; mean difference, 38,715), whereas anxiety is perceived higher by the group below 25 years of age.

Occupation, incomes, age and sex have no effect on stress. Family status has effect on stress $(\mathrm{F}=4922 ; p<0.016)$. Married experience less stress compared to those living in cohabitation (mean difference $-1.92 ; p<0.005$ ) and single (mean difference $-1.81 ; p<0.007)$. This result replicates that married people are significantly happier compared to couples living in common law (cohabitation) (Mastekaasa, 1994; Glenn, 1998; Myers, 2000).

For anxiety sex, occupation, age, family status, and incomes, have no effect.

For depression sex and incomes have no effect. Occupation has effect ( $\mathrm{F}=$ 8.1895; $p<0.005)$. Those who solely study experience more depression (2.05) compared to those who both study and work (1.60). Age has slight effect on depression in one aspect $(\mathrm{F}=3.215 ; p<0.44)$. Below 25 years of age the group reports more experienced depression compared to the group above $35 \mathrm{y}$. of age (mean difference $0.36 ; p<0.045$ ). Family status has partial effect on depression $(\mathrm{F}=3.182 ; p<0.45)$. Single experience more depression compared to these living in cohabitation (mean difference $0.41807 ; p<0.018$ ).

For happiness sex, family status, incomes and age have no effect. Occupation has effect $(\mathrm{F}=7.449 ; p<0.007)$ - those who both work and study, are happier compared to those who only study (4.13 vs. 3.71 ).

Sex and family status have no effect on flourishing. Age has effect-the group above 35 has higher score compared to the group below 25 years $(\mathrm{F}=3.982 ; p<$ 0.021 ; mean difference $0.42172 ; p<0.008)$. Occupation also has effect-those who only study (3.58) are less flourishing compared to those who study and work (4.11) $(\mathrm{t}=4.044 ; p<0.000)$. Subjective assessment of personal incomes also has effect $(\mathrm{F}=3.644 ; p<0.029)$. Those who assess their incomes as high are more flourishing compared to those who assess their incomes as low (mean difference $0.68304 ; p<0.010)$. 


\subsection{Selves Overlapping Effects on Attachment, Stress, Anxiety, Depression, Happiness, and Flourishing}

Out of all combinations solely real-ideal self overlapping turned out to have effect. Real-ideal selves overlapping has no effect on relationships avoidance, but has on relationships anxiety $(\mathrm{F}=2.826 ; p<0.028)$. The more is the overlapping, the less is the anxiety. Relationships anxiety is higher when there is no overlapping between real and ideal self compared to close selves (mean difference 0.82368; $p<0.007$ ), some overlapping (mean difference 0.58050; $p<0.048$ ) and most overlapping $(1.12778 ; p<0.005)$.

For flourishing the more is the overlapping between the real and ideal selves, the greater is the reported flourishing of the subjects. Real-virtual self overlapping has no effect. The group with most overlapping between real and ideal self ( $\mathrm{F}=5.195 ; p<0.001)$ is much more flourishing compared to the great distance (mean difference 0.98654) and no overlapping (mean difference 0.74279). Some overlapping group flourishes more compared to the group with great distance (mean difference 0.95266 ), no overlapping (mean difference 0.70891 ) and close one to the other (mean difference 0.34148 ).

The effect of ideal-virtual self overlapping is also significant $(\mathrm{F}=3.720 ; p<$ 0.007). The group with some overlapping is more flourishing compared to no overlap (mean difference 0.55687 ) and close one to the other (mean difference 0.35232). The most overlapping exceed in flourishing compared to no overlapping (mean difference 0.78346) and close one to the other (mean difference 0.57890). The more is the overlapping between ideal and virtual selves, the more is the flourishing.

\subsection{Attachment Style Effects on Stress, Anxiety, Depression, Happiness and Flourishing}

Attachment style has effect on perceived stress ( $\mathrm{F}=7.377 ; p<0.000)$. Fearful avoidant perceive more stress compared to dismissing avoidant (mean difference 0.77775) and secure (mean difference 0.77334). Preoccupied experience more stress compared to secure (mean difference 0.54753 ) and dismissing avoidant (mean difference 0.55194).

The effect of attachment on anxiety is significant $(\mathrm{F}=7.833 ; p<0.000)$. Securely attached perceive less anxiety compared to all other groups (fearful avoidant-mean difference -0.87444 ; dismissing avoidant -0.00244 ; preoccupied $-0.69461)$. Fearful avoidant are more anxious compared to dismissing avoidant (0.87200) and preoccupied (0.17983). Preoccupied experience more anxiety compared to dismissing avoidant (0.69217).

The effect of attachment on depression is also significant $(\mathrm{F}=5.509 ; p<$ 0.001 ). Securely attached experience less depression compared to fearful avoidant (mean difference $-0.87444 ; p<0.000$ ) and preoccupied (mean difference $-0.69641 ; p<0.005$ ); fearful avoidant are more depressive compared to dismissing avoidant (mean difference 0.87200; $p<0.000$ ); dismissing avoidant are less 
depressive compared to preoccupied (mean difference $-0.69217 ; p<0.000$ ).

Attachment style has effect also on happiness ( $\mathrm{F}=5.985 ; p<0.001)$. Fearful avoidant subjects are less happy compared to all other groups -secure (mean difference -0.84975 ), dismissing avoidant (mean difference -0.74812 ) and preoccupied (mean difference -0.66138 ).

Attachment has significant effect on flourishing ( $\mathrm{F}=10.259 ; p<0.000)$. Securely attached are more flourishing compared to fearful avoidant (mean difference 1.01047; $p<0.000$ ), dismissing avoidant (mean difference 0.38453; $p<$ 0.027 ) and preoccupied (mean difference 0.44301; $p<0.019$ ). Fearful avoidant are less flourishing compared to dismissing avoidant (mean difference -0.62594 ; $p<0.000$ ) and preoccupied are better on flourishing than fearful avoidant (mean difference 0.56746; $p<0.003)$.

\subsection{Correlations among Variables}

Pearsons correlation coefficients are used to examine the associations between flourishing, self-congruence, happiness, attachment, stress, anxiety, depression, and differentiation (Table 4).

All variables have significant correlations with flourishing. Weak and medium positive correlations are found for selves overlapping, and negative with relationships anxiety and avoidance, stress, and anxiety. Strong relations are reported for depression (negative) and positive for happiness, and differentiation. Real-ideal self has weak positive relations with happiness, flourishing and differentiation and weak negative correlation with depression. Positive and negative correlations are in line with the expectations. Differentiation correlates positively with real-ideal self overlapping, happiness and flourishing and negatively with relationships avoidance and anxiety, stress, anxiety and depression. Happiness has weak positive correlation with real-ideal self and strong positive correlations with differentiation and flourishing. Relationships avoidance is positively related to depression and negatively to differentiation, happiness, and flourishing.

Table 4. Correlations among the variables.

\begin{tabular}{|c|c|c|c|c|c|c|c|c|}
\hline & real-virtual self & ideal-virtual self & stress & anxiety & depression & happiness & differentiation & flourishing \\
\hline real-ideal self & $0.229^{*}$ & $0.367^{\star \star}$ & & & $-0.245^{\star \star}$ & $0.293^{\star *}$ & $0.392^{\star *}$ & $0.404^{\star \star}$ \\
\hline real-virtual self & & $0.431^{* *}$ & & & & & & \\
\hline ideal-virtual self & & & & & & & & $0.226^{*}$ \\
\hline relationships avoidance & & & & & $0.221^{\star}$ & $-0.270^{\star *}$ & $-0.249^{* *}$ & $-0.361^{\star *}$ \\
\hline relationships anxiety & & & $0.485^{\star *}$ & $0.479^{\star *}$ & $0.362^{\star *}$ & $-0.233^{\star *}$ & $-0.393^{\star *}$ & $-0.365^{\star *}$ \\
\hline stress & & & & $0.707^{\star *}$ & $0.570^{* *}$ & $-0.281^{\star *}$ & $-0.387^{\star *}$ & $-0.306^{\star *}$ \\
\hline anxiety & & & & & $0.560^{* *}$ & $-0.260^{\star \star}$ & $-0.427^{\star \star}$ & $-0.366^{\star *}$ \\
\hline depression & & & & & & $-0.613^{\star \star}$ & $-0.588^{\star \star}$ & $-0.651^{\star \star}$ \\
\hline happiness & & & & & & & $0.596^{* *}$ & $0.650^{\star *}$ \\
\hline differentiation & & & & & & & & $0.894^{\star \star}$ \\
\hline
\end{tabular}

${ }^{*}$ Correlation is significant at the 0.05 level (2-tailed). ${ }^{* *}$ Correlation is significant at the 0.01 level (2-tailed). 
Relationships anxiety correlates moderately positively with stress, anxiety and depression and negatively with differentiation, happiness and flourishing. Stress, anxiety and depression have moderate and strong positive correlations. Relationships avoidance does not correlate with stress and anxiety. The congruence between selves have weak to medium positive relations.

\subsection{Main Effects of Independent Variables and Predictors of Flourishing}

Figure 2 describes the main effects of self-congruence, attachment, stress, anxiety, depression, happiness and differentiation on flourishing.

Real-ideal self overlapping explains $1 \%$ of variance in ideal-virtual self ( $\mathrm{F}=$ 6674; $p<0.011 ; \mathrm{CI}=95 \%)$ and $13 \%$ of the variance in real-virtual self $(\mathrm{F}=$ $18,821 ; p<0.000 ; \mathrm{CI}=95 \%), 1 \%$ of depression $(\mathrm{FF}=7745 ; p<0.008 ; \mathrm{CI}=95 \%)$, $1 \%$ of variance in happiness $(\mathrm{F}=11,384 ; p<0.000 ; \mathrm{CI}=95 \%)$ and $13 \%$ of the variance in flourishing $(\mathrm{F}=19,590 ; p<0.000 ; \mathrm{CI}=95 \%)$.

Happiness explains $41 \%$ of the variance in flourishing ( $\mathrm{F}=84,451 ; p<0.000$; $\mathrm{CI}=95 \%)$. Stress accounts $1 \%$ of flourishing variance $(\mathrm{F}=12,515 ; p<0.001 ; \mathrm{CI}=9$ $5 \%)$, anxiety accounts $13 \%$ of flourishing variance $(\mathrm{F}=18,664 ; p<0.000 ; \mathrm{CI}=$ $95 \%)$, depression accounts for $40 \%$ of the variance in flourishing ( $\mathrm{F}=82,026 ; p<$ 0.000 ; $\mathrm{CI}=95 \%)$. Relationships avoidance explains $12 \%$ of the variance in flourishing $(\mathrm{F}=16,949 ; p<0.000 ; \mathrm{CI}=95 \%)$ and relationships anxiety $-13 \%(\mathrm{~F}=$ 18,403; $p<0.000 ; \mathrm{CI}=95 \%)$.

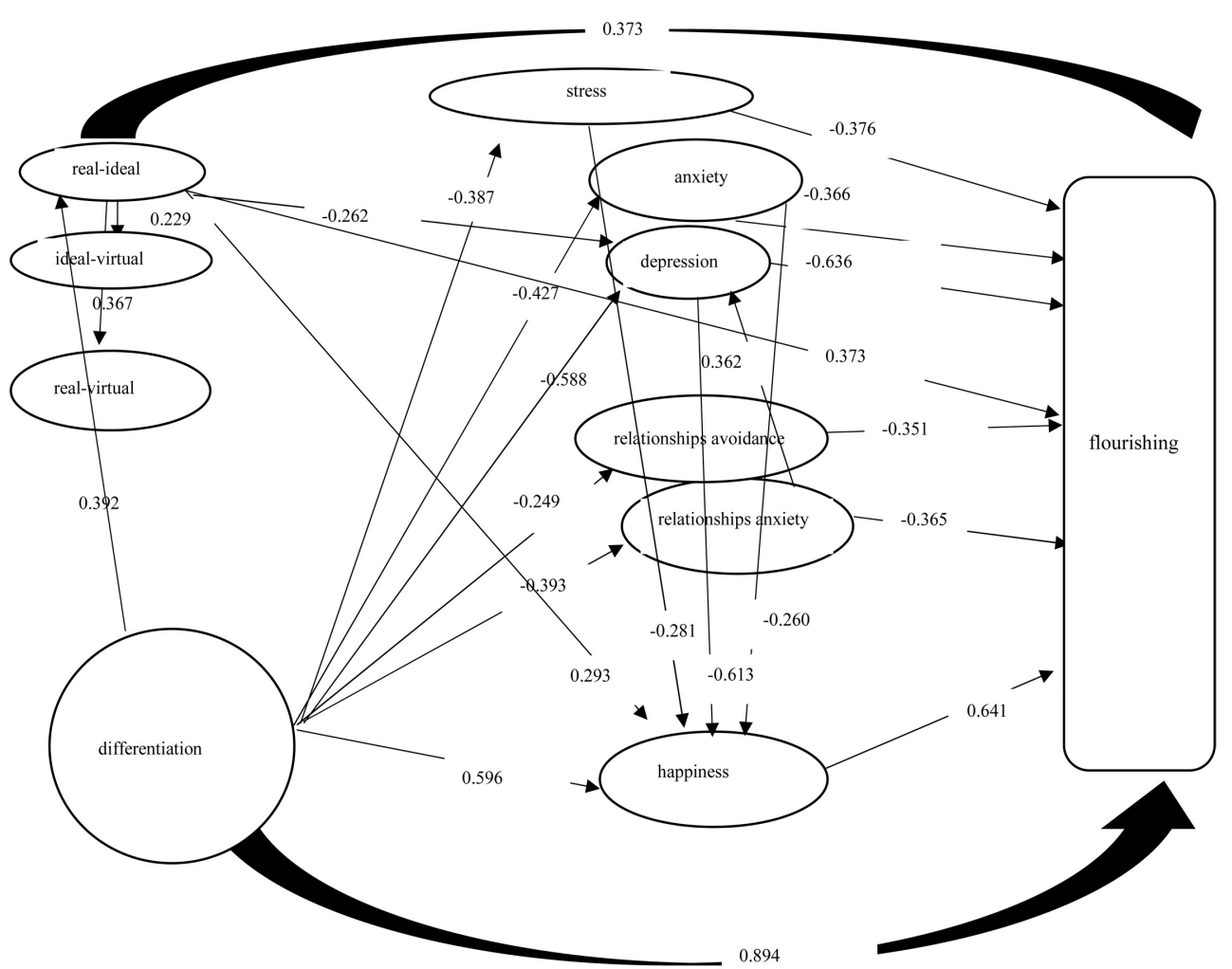

Figure 2. Main effects on flourishing. 
Relationships anxiety explains $13 \%$ of the dispersion of depression $(\mathrm{F}=$ 18,054; $p<0.000 ; \mathrm{CI}=95 \%)$.

Stress explains $1 \%$ of the variance in happiness $(\mathrm{F}=10,336 ; p<0.006 ; \mathrm{CI}=$ $95 \%)$ and $1 \%$ of the variance in flourishing ( $\mathrm{F}=12,515 ; p<0.001 ; \mathrm{CI}=95 \%)$.

Anxiety accounts $1 \%$ of the variance in happiness $(\mathrm{F}=8737 ; p<0.004 ; \mathrm{CI}=$ $95 \%)$ and $13 \%$ of the variance in flourishing $(\mathrm{F}=18,664 ; p<0.000 ; \mathrm{CI}=95 \%)$.

Depression accounts for $38 \%$ of the variance in happiness $(\mathrm{F}=72,983 ; p<$ $0.000 ; \mathrm{CI}=95 \%)$ and $40 \%$ of the variance in flourishing $(\mathrm{F}=82,026 ; p<0.000$; $\mathrm{CI}=95 \%)$.

Differentiation explains $15 \%$ of real-ideal self-congruence $(\mathrm{F}=18,403 ; p<$ 0.000 ; $\mathrm{CI}=95 \%), 26 \%$ of the variance in happiness $(\mathrm{F}=18,403 ; p<0.000 ; \mathrm{CI}=$ $95 \%)$ and $80 \%$ of the variance in flourishing ( $\mathrm{F}=479,420 ; p<0.000 ; \mathrm{CI}=95 \%)$. Furthermore, it accounts for $15 \%$ of the variance in stress $(\mathrm{F}=21,268 ; p<0.000$; $\mathrm{CI}=95 \%), 18 \%$ of the variance in anxiety $(\mathrm{F}=26,966 ; p<0.000 ; \mathrm{CI}=95 \%)$ and $35 \%$ of the variance in depression $(\mathrm{F}=63,975 ; p<0.000 ; \mathrm{CI}=95 \%)$. Differentiation explains also $1 \%$ of the variance in relationships avoidance $(\mathrm{F}=7986 ; p<$ $0.006 ; \mathrm{CI}=95 \%)$ and $15 \%$ of the variance in relationships anxiety $(\mathrm{F}=21,979 ; p<$ 0.000; CI = 95\%).

The better is the real-ideal self-congruence, the less is the perceived depression and the higher the experienced happiness and flourishing. The lower experienced stress, anxiety and depression result in higher happiness and flourishing. And the higher are the skills for differentiation of social roles and life domains, the less experienced are negative states-stress, anxiety, and depression, lower are the relationships avoidance and anxiety and higher the perceived happiness and flourishing.

For predictors of flourishing the results from the linear multiple logistic regression analysis, including self-congruence, relationships avoidance and relationships anxiety, stress, anxiety, depression and happiness,reveal that they account $61 \%$ of the variance with predictors depression, happiness, real-ideal congruence, relationships avoidance and relationships anxiety $(\mathrm{F}=35,812$; $p<$ 0.000; $\mathrm{CI}=95 \%$ ) (Figure 3).

On the second step when we control for these variables with hierarchical regression analysis for the effect of differentiation, the explained variance in flourishing is $84 \%(\mathrm{~F}=99.413 ; p<0.000 ; \mathrm{CI}=95 \%)$. Differentiation explains further $23 \%$ of the variance, whereas real-ideal self and relationships anxiety are not significant individual predictors in this model. Figure 4 depicts the model of flourishing and the main effect of differentiation on flourishing and its predictors.

Differentiation explains $14 \%$ of the variance in relationships anxiety ( $\mathrm{F}=$ 21.979; $p<0.000)$ and $14 \%$ of the variance in real-ideal overlapping $(\mathrm{F}=21.906$; $p<0.000)$. The explained variation of depression is $35 \%(\mathrm{~F}=63,975 ; p<0.000)$, of happiness $36 \%(\mathrm{~F}=66,627 \mathrm{l} ; p<0.000)$, and of relationships anxiety-16\% (F = $21,979 ; p<0.000)$.

For happiness linear multiple regression accounted only two predictors. 


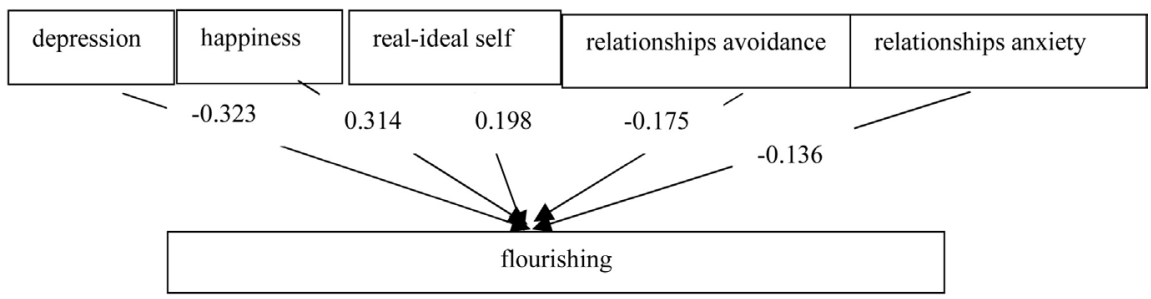

Figure 3. Model of flourishing predictors.

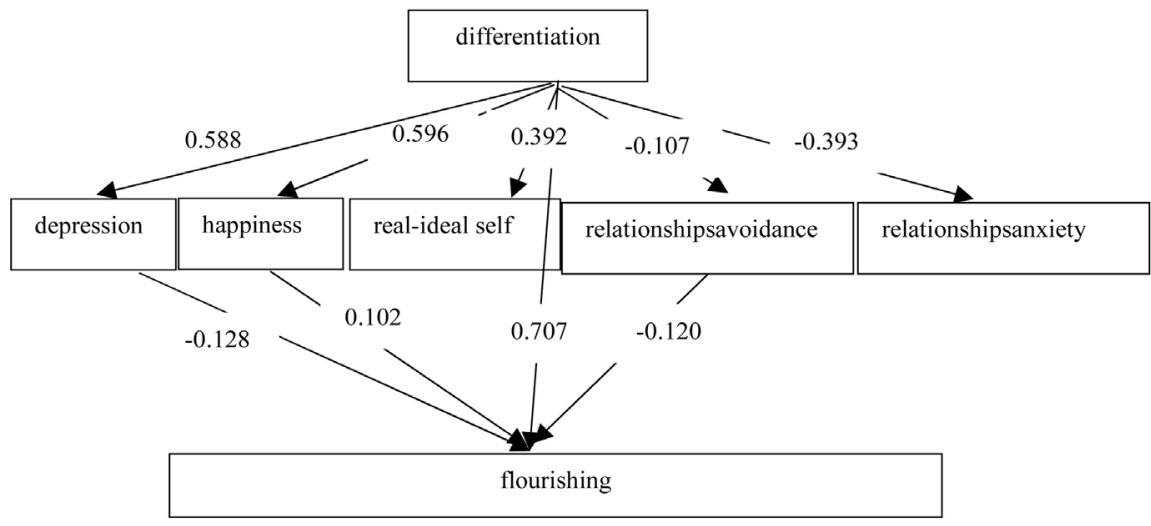

Figure 4. Differentiation as predictor of flourishing with control for self congruence, relational avoidance, depression and happiness.

Differentiation is excluded and only flourishing and depression predict higher perceived happiness. The model explains $48 \%$ of the variance in happiness. No other categorical and continuous variables inclusion accounted for a change $\mathrm{F}=$ 37.154; $p<0.000 ; \mathrm{CI}=95 \%)$. The standard $\beta$ of flourishing effect is 0.434 and of depression -0.331 .

\section{Discussion}

The general results reveal that for self-congruence accounted is rather closeness than distance. The highest is the overlapping of real-virtual self, followed by real-ideal self and ideal-virtual self. Furthermore, highest is the percent of reported "some overlapping", which is indicative for the self-reflection and objective reporting. Real-virtual self has most overlapping, meaning that virtual reality really is a kind of supposed adaptive coping strategy in view to the lack of extreme results. Difference in means is accounted between real-virtual and idealvirtual selves with more overlapping for real-ideal self. This suggests that virtual self is closely related to the real than to the ideal, e.g., we try to construe virtual self in a manner, compensating and/or expanding our real, but not ideal image of self. Ideal self is not supposed to be implicated in virtual world, which also supports this prediction and deserves to be studied further.

One fourth of the sample is securely attached, whereas the remaining attachment styles are also equally distributed. Stress, anxiety and depression are low for the studied subjects. In general, subjects report high level of happiness, especially assessing their life in general. In view to the comparison effect and virtual 
life, the statistically significant difference is accounted for lower levels of subjectively perceived happiness when subjects compare with their virtual friends. This is confirmation for the role of the reference framework on the emotional component of well-being and that virtual environment can provoke significant discrepancies due to the desirable and ought self-representations and norms.

Flourishing scores of all subjects are above the middle point. This deserves special attention in view to the noted specificity of very high percent of life dissatisfaction in Bulgaria. Good indication is also that in respect to differentiation $52 \%$ of the participants have good abilities to differentiate their social roles and life domains and thus, maintain self-concepts in any of them, $20 \%$ have medium differentiation of social roles and life domains and $28 \%$ are low on differentiation or have not enough skills to differentiate the social roles and self-perceptions in various life domains. Selves reasonable overlapping at least to some extent and the fact that more than half of the subjects are well equipped with differentiation abilities, can explain the higher reported levels of happiness and flourishing.

Correlations reveal that the closer are the self-concepts in one domain, the closer they are in the others. In other words, if real-ideal self-overlapping is higher, this suggests more overlapping between real and virtual self and ideal and virtual self. Real-ideal self-overlapping along with ideal-virtual self-overlapping are related to flourishing. Self-congruence is related also to higher differentiation and happiness and the more is the self-congruence, the less is the reported depression. High differentiation is related to higher happiness and flourishing. Maintaining lower stress, anxiety and depression leads to higher perceived happiness and flourishing. Increase in happiness is related to increase of flourishing.

Figure 5 describes all main effects on flourishing and its predictors.

Important to be noted is the almost no effect of socio-demographic variables. Sex, family status, incomes and occupation, have no effect on the relationships avoidance and anxiety. This supports that attachment style is fixed early and

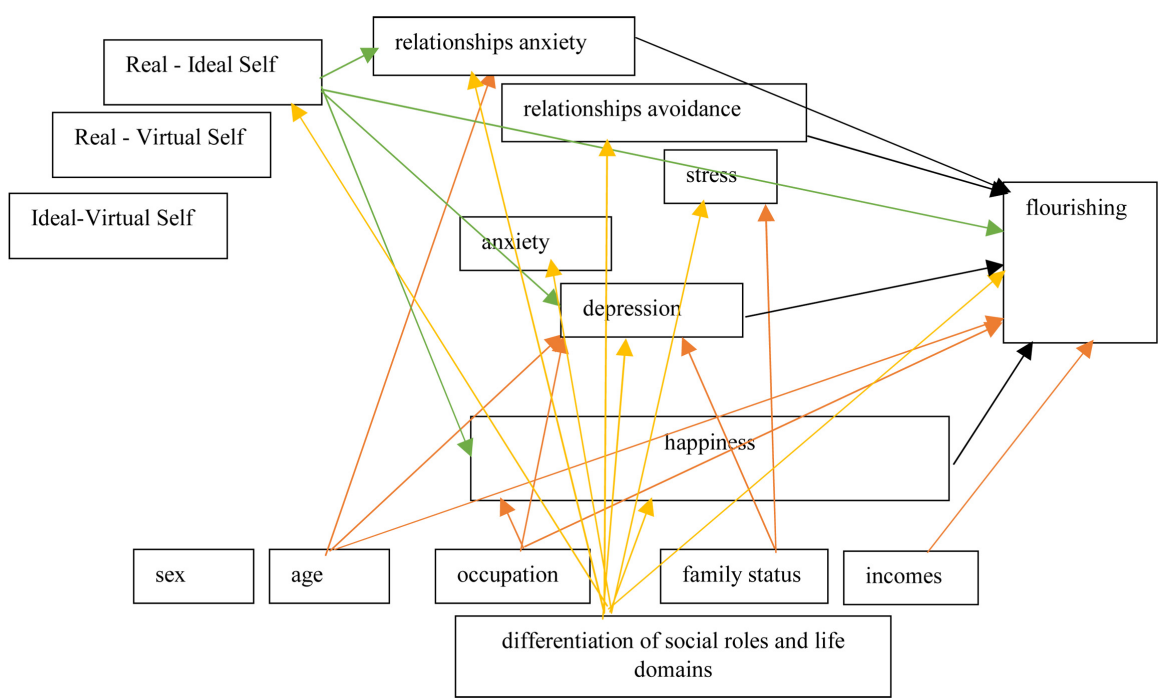

Figure 5. Model of studied variables and all accounted effects. 
afterwards replicated in adulthood. Age has partial effect on relationships anxiety-students below 25 of age perceive higher anxiety compared to the students above 35 years of age. It can be suggested that anxiety in attachment is dependant to some extent on social experience. Occupation, incomes, age and sex, have no effect on stress, which supports that stress is invoked by unexpected or chronically stressful transactions between individual and environment. Following the emotional and cognitive model of coping strategies in support to the role of emotional support, is the result that family status has effect on stress-married subjects experience less stress compared to those living in cohabitation. For anxiety sex, occupation, age, family status, incomes, have no effect, supporting that it is trait. For depression sex and incomes have no effect. Occupation has effect-those who solely study experience more depression compared to those who both study and work. Age accounts some effect on depression-students below 25 years of age report more experienced depression compared to the group above 35 years of age. In other words, age and more daily tasks obviously leave less room for depressive states due to the fact that people find coping strategies to manage their emotions and regulate stress levels. Meaning, given by employment and life experience, promote this.

Family status has partial effect on depression-single experience more depression compared to these living in cohabitation. This is interesting compared to the experienced less stress. Depression obviously is not suppressed in marriage because of the daily challenges of the routine, which may be slightly different in cohabitation. For happiness sex, family status, incomes and age have no effect. However, occupation confirms for the emotional component of well-being also that those who both work and study, are happier compared to those who only study.

Sex and family status have no effect on flourishing. Age has effect-the group above 35 scores higher on flourishing compared to the group below 25 years of age. This is replication for the suggestion that self-realization and self-actualization are reasonably attained about 36 years of age. Relationships avoidance turns out to be fixed in early childhood, whereas anxiety is to some extent age-dependant. Occupation also has effect-those who only study, are less flourishing compared to those who study and work. This result supports the goals and meaning role for flourishing, giving experience of the sense. External support is confirmed in the influence of incomes-those who assess their incomes as high are more flourishing compared to those who assess their incomes as low. In general, socio-demographic variables have almost no effect except for confirmation of the age effect for self-realization in general and occupation, supposed to give meaning. In view to flourish, person needs to be equipped both with personal resources and confirmation for the efforts in the real world, e.g. better paid job.

Out of all combinations solely real-ideal self-overlapping turned out to have effect on the other variables. This can be explained with the lack of significant differences, accounted for virtual-ideal and real-virtual selves. Real-ideal selves 
overlapping has no effect on relationships avoidance, but has on relations anxiety. The more is the overlap, the less is the anxiety. Relationships anxiety is higher when there is no overlapping between real and ideal selves. Furthermore, the more is the overlapping, the higher is the experienced happiness and less the reported depression. For flourishing the more is the overlapping between real and ideal selves, the greater is the reported flourishing of the subjects. Real-virtual self overlapping has no effect on flourishing-this means that flourishing is rather rational and self-reflection is based on the real self, virtual self provides compensation mostly emotionally. The only accounted effect of congruence between ideal and virtual self-overlapping is also for flourishing. The more is the overlapping between ideal and virtual selves, the more is the flourishing. In conclusion, real-ideal self-congruence promotes happiness and flourishing and at the same time has effect on mitigating depressive states and relationships anxiety.

Attachment style has effect on perceived stress, anxiety and depression. The higher are the anxiety and avoidance in attachment, the more is the perceived stress. Securely attached people perceive less anxiety compared to all other attachment styles. Furthermore, they experience less depression compared to groups with higher relationships avoidance and anxiety. Secure relations with others result in less perceived negative emotions. On the contrary, they promote the perceived happiness, which is based to great extent on the quality of the relations with others. Securely attached individuals are more flourishing compared to all other groups, high either on anxiety or avoidance in the relations.

The group high in differentiation reports higher happiness. The higher is the differentiation, the higher is the flourishing. Good differentiation abilities and skills result in better relations with others, less depressive states and higher happiness and flourishing. Furthermore, differentiation promotes overlapping of real and virtual self. This supports the idea of promoting personal abilities as early as possible and throughout life as people to differentiate their social roles and life domains. In this way they will be equipped with better self-reflection capacity to maintain various self-concepts and identities depending on the life domain. Differentiation has main effect on all variables. The higher is the differentiation, the less are: stress, anxiety, and depression and the less are the relationships avoidance and anxiety. On the contrary, promoted are self congruence, happiness and flourishing. This supports the idea that differentiation can be considered preventive and proactive coping strategy, which can be easily learnt and draws attention on the need of interventions in this line.

After studying the main effects, we traced the prediction of self-congruence, attachment, stress, anxiety, depression and happiness and afterwards controlled them to account the differentiation effect in hierarchical regression. Our expectations were confirmed-as outlined in the above-referred research, this study also confirmed the effect of self-congruence and attachment on flourishing and the relations with stress and depression. We suggest the lot of main effects, not 
confirmed in the models, is due to the vast area, comprising flourishing (and happiness). These are both intrinsic motivation and reflection and the extrinsic pressures, harmonized with personal goals. We plan to extend the study along this line, however in this study we were challenged most of all to make initial research of flourishing in view to have initial idea, supplementing the previously collected well-being results, and test the role of differentiation as a pathway to well-being and flourishing.

Differentiation furthermore predicts higher happiness and real ideal overlapping, as well as less relationships avoidance and anxiety, stress, anxiety and depression.

Linear multiple regression revealed that predictors, accounting for $61 \%$ of flourishing variance, are depression, happiness, self-congruence, relationships avoidance and relationships anxiety. Inclusion of differentiation raisedthe explained variance in flourishing to $84 \%$. Real-ideal self and relationships anxiety, however, are not significant individual predictor in this model, i.e. their effect is mediated by the strong effect of differentiation. For happiness, multiple regression accounted only two predictors. Differentiation is excluded and only flourishing and depression predict higher perceived happiness. They explain $48 \%$ of the variance in happiness. Thus, differentiation as cognitive process and self-reflection turns out to be important both for emotional well-being individually and for flourishing as part of the model of predictors. Its implications concern flourishing, which can be explained by the nature of the concept, comprising meaning and satisfaction. Happiness as emotional subjective experience is related mainly to inner subjective experience. This, however, does not exclude the role of the individual direct effect of differentiation on happiness as well.

The confirmed strong effect of differentiation leads to the conclusion that techniques and learning how to flourish can be based on simple self-reflection attitude for the different social roles and finding ways to self-growth and assessing one's accomplishments. Flourishing is supported by differentiation skills and more areas of engagement in search and finding meaning. Self-awareness and management of individual states is the model of learning how to be happy and flourishing.

\section{Conclusion, Limitations and Future Research}

Flourishing predictors are differentiation, happiness, low depression and relationships avoidance. In addition, the main effect of differentiation on both flourishing and all its predictors is accounted. Flourishing people tend to differentiate better the social roles and significant life domains and this helps them be more self-reflective and maintain flexible crystallizing identity. This leads to the conclusion on the importance of interventions to equip individuals with good differentiation abilities throughout life cycle. In view the stress and expectations to achievements to be harmonized with the personal strives and the self-realization to be successful, one of the lifelong learning objectives is forming attitudes 
toward individual creativity in self-awareness and adaptation to the dynamic inner and outer changes. We consider differentiation one of the ways to learn to flourish.

The results of our study are limited by the use of a cross-sectional design and convenience sample, which makes it difficult to draw general conclusions. The findings of the current study have implications for future research and practice. For Bulgarian specificity, it shall be noted that flourishing of the participants in the study is high, notwithstanding the cross-cultural and national results, revealing high prevalence of life dissatisfaction. This primary study gives raise for a number of future directions and suggested interventions. We can hypothesise that future research might explore beneficial pathways to flourishing, especially through differentiation.

\section{Conflicts of Interest}

The author declares no conflicts of interest regarding the publication of this paper.

\section{References}

Ainsworth, M. D. S., Blehar, M. C., Waters, E., \& Wall, S. (1978). Patterns of Attachment: A Psychological Study of the Strange Situation. Hillsdale, NJ: Lawrence Erlbaum.

Antonovsky, A. (1979). Health, Stress, and Coping. San Francisco, CA: Jossey-Bass.

Arnett, J. J. (2000). Emerging Adulthood: A Theory of Development from the Late Teens through the Twenties. The American Psychologist, 55, 469-480.

https://doi.org/10.1037/0003-066X.55.5.469

Aron, A., Aron, E. N., \& Smollan, D. (1992). Inclusion of Other in the Self Scale and the Structure of Interpersonal Closeness. Journal of Personality and Social Psychology, 63, 596-612. https://doi.org/10.1037/0022-3514.63.4.596

Back, M. D., Stopfer, J. M., Vazire, S., Gaddis, S., Schmukle, S. C., Egloff, B. et al. (2010). Facebook Profiles Reflect Actual Personality, Not Self-Idealization. Psychological Science, 21, 372-374. https://doi.org/10.1177/0956797609360756

Bakalova, B., Bakracheva, M., \& Mizova, B. (2015). Happiness and Life Satisfaction: In Search for Ourselves. Sofia: Colbis. (In Bulgarian)

Bakracheva, M. (2009). Identity in 3 Steps. Sofia: Paradigma (In Bulgarian).

Bakracheva, M. (2016). Escape from Happiness... or Happy Despite of the Environment. Sofia: Colbis. (In Bulgarian)

Bakracheva, M. (2017). Identity and Cooping with Stress. Sofia: Colbis. (In Bulgarian)

Bakracheva, M., \& Bakalova, D. (2011). Research Framework, Conceptualizing Virtual Identity as a Domain of e-Consumer's Psychosocial Identity. Bulgarian Journal of Psychology, 1-2, 63-82. (In Bulgarian)

Bakracheva, M., Bakalova, D., \& Mizova, B. (2014). Effects of Comparison in Real and Virtual Environment on Happiness and Life Satisfaction. In Proceedings, VII Congress of Psychology (pp. 257-271). Sofia. (In Bulgarian)

Bartholomew, K., \& Horowitz, L. M. (1991). Attachment Styles among Young Adults: A Test of a Four-Category Model. Journal of Personality and Social Psychology, 61, 226-244. https://doi.org/10.1037/0022-3514.61.2.226

Beck, A. T. (1967). Depression: Clinical, Experimental, and Theoretical Aspects. Phila- 
delphia, PA: University of Pennsylvania Press.

Behm-Morawitz, E. (2013). Mirrored Selves: The Influence of Self-Presence in a Virtual World on Health, Appearance, and Well-Being. Computers in Human Behavior, 29, 119-128. https://doi.org/10.1016/j.chb.2012.07.023

Bessière, K., Seay, A. F., \& Kiesler, S. (2007). The Ideal Elf: Identity Exploration in World of Warcraft. CyberPsychology \& Behavior, 10, 530-535. https://doi.org/10.1089/cpb.2007.9994

Bifulco, A., Moran, P. M., Ball, C., Jacobs, C., Baines, R., \& Bunn, A. (2002). Childhood Adversity, Parental Vulnerability and Disorder: Examining Inter-Generational Transmission of Risk. Journal of Child Psychology and Psychiatry, 43, 1075-1086.

https://doi.org/10.1111/1469-7610.00234

Bowlby, J. (1969). Attachment and Loss: Vol. 1. Attachment. New York: Basic Books.

Bowlby, J. (1979). The Making and Breaking of Affectional Bond. New York: Basic Books.

Brand, M., Laier, C., \& Young, K. (2014). Internet Addiction: Coping Styles, Expectancies, and Treatment Implications. Frontiers in Psychology, 5, 1256. https://doi.org/10.3389/fpsyg.2014.01256

Brooks, S. (2015). Does Personal Social Media Usage Affect Efficiency and Well-Being? Computers in Human Behavior, 46, 26-37. https://doi.org/10.1016/j.chb.2014.12.053

Carnelley, K. B., Pietromonaco, P. R., \& Jaffe, K. (1994). Depression, Working Models of Others, and Relationship Functioning. Journal of Personality and Social Psychology, 66, 127-140. https://doi.org/10.1037/0022-3514.66.1.127

Carver, C. S., Lawrence, J. W., \& Scheier, M. F. (1999). Self-Discrepancies and Affect: Incorporating the Role of Feared Selves. Personality and Social Psychology Bulletin, 25, 783-792. https://doi.org/10.1177/0146167299025007002

Cassidy, J., \& Shaver, P. R. (Eds.) (1999). Handbook of Attachment: Theory, Research and Clinical Applications. New York: Guilford.

Cheung, S. K. (1997). Self-Discrepancy and Depressive Experiences among Chinese Early Adolescents: Significance of Identity and the Undesired Self. International Journal of Psychology, 32, 347-359. https://doi.org/10.1080/002075997400700

Clark, L., \& Watson, D. (1991). Tripartite Model of Anxiety and Depression: Psychometric Evidence and Taxonomic Implications. Journal of Abnormal Psychology, 100, 316-336. https://doi.org/10.1037/0021-843X.100.3.316

Cooper, A. J., Perkins, A. M., \& Corr, P. J. (2007). A Confirmatory Factor Analytic Study of Anxiety, Fear, and Behavioral Inhibition System Measures. Journal of Individual Differences, 28, 179-187. https://doi.org/10.1027/1614-0001.28.4.179

Crowe, N. (2010). “It's Like My Life but More, and Better!”-Playing with the Cathaby Shark Girls: MMORPGs, Young People and Fantasy-Based Social Play. International Journal of Adolescence and Youth, 16, 201-223. https://doi.org/10.1080/02673843.2011.9748055

Diener, E. (1984). Subjective Well-Being. Psychological Bulletin, 95, 542-575. https://doi.org/10.1037/0033-2909.95.3.542

Diener, E., \& Ryan, K. (2009). Subjective Well-Being: A General Overview. South African Journal of Psychology, 39, 391-406. https://doi.org/10.1177/008124630903900402

Diener, E., Smith, H., \& Fujita, F. (1995). The Personality Structure of Affect. Journal of Personality and Social Psychology, 69, 130-141. https://doi.org/10.1037/0022-3514.69.1.130

Diener, E., Suh, E. M., Lucas, R. E. L., \& Smith, H. L. (1999). Subjective Well-Being: Three 
Decades of Progress. Psychological Bulletin, 125, 276-302.

https://doi.org/10.1037/0033-2909.125.2.276

Diener, E., Wirtz, D., Tov, W., Kim-Prieto, C., Choi, D., Oishi, S., \& Biswas-Diener, R. (2009). New Measures of Well-Being: Flourishing and Positive and Negative Feelings. Social Indicators Research, 39, 247-266. https://doi.org/10.1007/978-90-481-2354-4_12

Eysenck, H. J. (1967). The Biological Basis of Personality. Springfield, NJ: Thomas.

Fox, J., \& Moreland, J. J. (2015). The Dark Side of Social Networking Sites: An Exploration of the Relational and Psychological Stressors Associated with Facebook Use and Affordances. Computers in Human Behavior, 45, 168-176. https://doi.org/10.1016/j.chb.2014.11.083

Fraley, R. C., Waller, N. G., \& Brennan, K. A. (2000). An Item Response Theory Analysis of Self-Report Measures of Adult Attachment. Journal of Personality and Social Psychology, 78, 350-365. https://doi.org/10.1037/0022-3514.78.2.350

Freud, S. (1957). On Narcissism: An Introduction. In J. Strachey (Ed. and Trans.), Standard Edition (Vol. 14, pp. 73-102). London: Hogarth Press. (Original work published 1914)

Glenn, N. D. (1998). The Course of Marital Success and Failure in Five American 10-Year Marriage Cohorts. Journal of Marriage and the Family, 60, 569-576. https://doi.org/10.2307/353529

Goldberg, L. R. (1992). The Development of Markers for the Big-Five Factor Structure. Psychological Assessment, 4, 26-42. https://doi.org/10.1037/1040-3590.4.1.26

Haferkamp, N., Eimler, S. C., Papadakis, A.-M., \& Kruck, J. V. (2012). Men Are from Mars, Women Are from Venus? Examining Gender Differences in Self-Presentation on Social Networking Sites. Cyberpsychology, Behavior, and Social Networking, 15, 91-98. https://doi.org/10.1089/cyber.2011.0151

Higgins, E. T. (1987). Self-Discrepancy: A Theory Relating Self and Affect. Psychological Review, 94, 319-340. https://doi.org/10.1037/0033-295X.94.3.319

Higgins, E. T., Klein, R., \& Strauman, T. (1985). Self-Concept Discrepancy Theory: A Psychological Model for Distinguishing among Different Aspects of Depression and Anxiety. Social Cognition, 3, 51-76. https://doi.org/10.1521/soco.1985.3.1.51

Hobfoll, S. E., Freedy, J. R., Green, B. L., \& Solomon, S. D. (1996). Coping Reactions to Extreme Stress: The Roles of Resource Loss and Resource Availability. In M. Zeidner, \& N. S. Endler (Eds.), Handbook of Coping: Theory, Research, Applications (pp. 322-349). New York: Wiley.

Horney, K. (1950). Neurosis and Human Growth. New York: Norton.

Huta, V., \& Ryan, R. M. (2010). Pursuing Pleasure or Virtue: The Differential and Overlapping Well-Being Benefits of Hedonic and Eudaimonic Motives. Journal of Happiness Studies: An Interdisciplinary Forum on Subjective Well-Being, 11, 735-762. https://doi.org/10.1007/s10902-009-9171-4

Huyck, M. H. (1993). Middle Age. Academic American Encyclopaedia, 13, 390-391.

James, W. (1890). The Principles of Psychology. New York: Holt. https://doi.org/10.1037/10538-000

Jardine, R., Martin, N. G., \& Henderson, A. S. (1984). Genetic Covariation between Neuroticism and the Symptoms of Anxiety and Depression. Genetic Epidemiology, 1, 89-107. https://doi.org/10.1002/gepi.1370010202

Keyes, C. L. M. (2002). The Mental Health Continuum: From Languishing to Flourishing in Life. Journal of Health and Social Behavior, 43, 207-222.

https://doi.org/10.2307/3090197 
Keyes, C. L. M. (2005). Mental Illness and/or Mental Health? Investigating the Axioms of the Complete State Model of Health. Journal of Consulting and Clinical Psychology, 73, 539-548. https://doi.org/10.1037/0022-006X.73.3.539

Keyes, C. L. M. (2006). Mental Health in Adolescence: Is America's Youth Flourishing? American Journal of Orthopsychiatry, 76, 395-402. https://doi.org/10.1037/0002-9432.76.3.395

Keyes, C. L. M. (2007). Promoting and Protecting Mental Health as Flourishing: A Complementary Strategy for Improving National Mental Health. American Psychologist, 62, 95-108. https://doi.org/10.1037/0003-066X.62.2.95

Keyes, C. L. M., \& Simoes, E. J. (2012). To Flourish or Not: Positive Mental Health and All-Cause Mortality. American Journal of Public Health, 102, 2164-2172. https://doi.org/10.2105/AJPH.2012.300918

Keyes, C., Shmotkin, D., \& Ryff, C. D. (2002). Optimizing Well-Being: The Empirical Encounter of Two Traditions. Journal of Personality and Social Psychology, 82, 10071022. https://doi.org/10.1037/0022-3514.82.6.1007

Kobak, R. R., Sudler, N., \& Gamble, W. (1991). Attachment and Depressive Symptoms during Adolescence: A Developmental Pathways Analysis. Development and Psychopathology, 3, 461-474. https://doi.org/10.1017/S095457940000763X

Lachman, M. E. (2004). Development in Midlife. Annual Review of Psychology, 55, 305-331. https://doi.org/10.1146/annurev.psych.55.090902.141521

Lazarus, R. S. (1966). Psychological Stress and the Coping Process. New York: McGraw-Hill.

Lazarus, R. S. (1991). Emotion and Adaptation. New York: Oxford University Press.

Lazarus, R. S., \& Folkman, S. (1984). Stress, Appraisal, and Coping. New York: Springer.

Lazarus, R. S., \& Folkman, S. (1986). Cognitive Theories of Stress and the Issue of Circularity. In M. H. Appley, \& R. Trumbull (Eds.), Dynamics of Stress. Physiological, Psychologcal, and Social Perspectives (pp. 63-80). New York: Plenum. https://doi.org/10.1007/978-1-4684-5122-1_4

Lin, R., \& Utz, S. (2015). The Emotional Responses of Browsing Facebook: Happiness, Envy, and the Role of Tie Strength. Computers in Human Behavior, 52, 29-38. https://doi.org/10.1016/j.chb.2015.04.064

Lovibond, S. H., \& Lovibond, P. F. (1995). Manual for the Depression Anxiety \& Stress Scales (2nd ed.). Sydney: Psychology Foundation. http://www.psy.unsw.edu.au/dass/

Lyubomirsky, S., Sheldon, K. M., \& Schkade, D. (2005). Pursuing Happiness: The Architecture of Sustainable Change. Review of General Psychology, 9, 111-131. https://doi.org/10.1037/1089-2680.9.2.111

Manago, A. M., Graham, M. B., Greenfield, P. M., \& Salimkhan, G. (2008). Self-Presentation and Gender on MySpace. Journal of Applied Developmental Psychology, 29, 446-458. https://doi.org/10.1016/j.appdev.2008.07.001

Manolov, M. (2019). Self-Discrimination. Veliko Tarnovo: IVIS. (In Bulgarian)

Maslow, A. H. (1954). Motivation and Personality. New York: Harper \& Row.

Mastekaasa, A. (1994). The Subjective Well-Being of the Previously Married: The Importance of Unmarried Cohabitation and Time Since Widowhood or Divorce. Social Forces, 73, 665-692. https://doi.org/10.1093/sf/73.2.665

Mikulincer, M. (1995). Attachment Style and the Mental Representation of the Self. Journal of Personality and Social Psychology, 69, 1203-1215. https://doi.org/10.1037/0022-3514.69.6.1203

Mikulincer, M., Florian, V., \& Weller, A. (1993). Attachment Styles, Coping Strategies, 
and Posttraumatic Psychological Distress: The Impact of the Gulf War in Israel. Journal of Personality and Social Psychology, 64, 817-826.

https://doi.org/10.1037/0022-3514.64.5.817

Myers, D. G. (2000). The Funds, Friends, and Faith of Happy People. American Psychologist, 55, 56-67. https://doi.org/10.1037/0003-066X.55.1.56

Ogilvie, D. M. (1987). The Undesired Self: A Neglected Variable in Personality Research. Journal of Personality and Social Psychology, 52, 379-385. https://doi.org/10.1037/0022-3514.52.2.379

Perkins, A. M., Kemp, S. E., \& Corr, P. J. (2007). Fear and Anxiety as Separable Emotions: An Investigation of the Revised Reinforcement Sensitivity Theory of Personality. Emotion, 7, 252-261. https://doi.org/10.1037/1528-3542.7.2.252

Reich, A. (1954). Early Identifications as Archaic Elements in the Superego. Journal of the American Psychoanalytic Association, 2, 218-238. https://doi.org/10.1177/000306515400200203

Reinecke, M. A., \& Rogers, G. M. (2001). Dysfunctional Attitudes and Attachment Style among Clinically Depressed Adults. Behavioural and Cognitive Psychotherapy, 29, 129-141. https://doi.org/10.1017/S1352465801002016

Reiss, S., \& Havercamp, S. M. (2005). Motivation in a Developmental Context: A New Method for Studying Self-Actualization. Journal of Humanistic Psychology, 45, 41-53. https://doi.org/10.1177/0022167804269133

Rholes, S. W., \& Simpson, J. A. (2004). Adult Attachment: Theory, Research, and Clinical Implications. New York: Guilford.

Robin A., Lakey, B., \& Orehek, E. (2007). Links among Attachment Dimensions, Affect, the Self, and Perceived Support for Broadly Generalized Attachment Styles and Specific Bonds. Personality and Social Psychology Bulletin, 33, 340-353.

https://scholarworks.gvsu.edu/psy_articles/31 https://doi.org/10.1177/0146167206296102

Rogers, C. R. (1959). A Theory of Therapy, Personality, and Interpersonal Relationships: As Developed in the Client-Centered Framework. In S. Koch (Ed.), Psychology: A Study of a Science, Vol. 3, Formulations of the Person and the Social Context (pp. 184-256). New York: McGraw-Hill.

Rogers, C. R. (1961). On Becoming a Person: A Therapist's View of Psychotherapy. London: Constable.

Rosen, L. D., Whaling, K., Rab, S., Carrier, L. M., \& Cheever, N. (2013). Is Facebook Creating "iDisorders"? The Link between Clinical Symptoms of Psychiatric Disorders and Technology Use, Attitudes and Anxiety. Computers in Human Behavior, 29, 1243-1254. https://doi.org/10.1016/j.chb.2012.11.012

Roy-Byrne, P., Afari, N., Ashton, S., Fischer, M., Goldberg, J., \& Buchwald, D. (2002). Chronic Fatigue and Anxiety/Depression: A Twin Study. British Journal of Psychiatry, 180, 29-34. https://doi.org/10.1192/bjp.180.1.29

Ryan, R. M., Huta, V., \& Deci, E. L. (2008). Living Well: A Self-Determination Theory Perspective on Eudaimonia. Journal of Happiness Studies, 9, 139-170.

https://doi.org/10.1007/s10902-006-9023-4

Ryff, C. D. (1989). Happiness Is Everything, or Is It? Explorations on the Meaning of Psychological Well-Being. Journal of Personality and Social Psychology, 57, 1069-1081. https://doi.org/10.1037/0022-3514.57.6.1069

Ryff, C. D., \& Keyes, C. L. M. (1995). The Structure of Psychological Well-Being Revisited. Journal of Personality \& Social Psychology, 69, 719-727. 
https://doi.org/10.1037/0022-3514.69.4.719

Ryff, C. D., \& Singer, B. H. (2008). Understanding Healthy Aging: Key Components and Their Integration. In V. Bengtson, D. Gans, N. M. Putney, \& M. Silverstein (Eds.), Handbook of Theories of Aging (2nd ed., pp. 117-144). New York: Springer.

Scheier, M. F., \& Carver, C. S. (1992). Effects of Optimism on Psychological and Physical Well-Being: Theoretical Overview and Empirical Update. Cognitive Therapy and Research, 16, 201-228. https://doi.org/10.1007/BF01173489

Schwarzer, R., \& Leppin, A. (1991). Social Support and Health. A Theoretical and Empirical Overview. Journal of Social and Personal Relationships, 8, 99-127. https://doi.org/10.1177/0265407591081005

Seligman, M. E. P. (2002). Authentic Happiness. New York, NY: Free Press.

Seligman, M. E. P. (2011). Flourish: A Visionary New Understanding of Happiness and Well-Being. New York: Free Press.

Selye, H. (1976). The Stress of Life (rev. ed.). New York: McGraw-Hill.

Shek, D. T. L. (1996). Mid-Life Crisis in Chinese Men and Women. Journal of Psychology, 130, 109-119. https://doi.org/10.1080/00223980.1996.9914993

Sheldon, K. M., \& Lyubomirsky, S. (2009). Change Your Actions, Not Your Circumstances: An Experimental Test of the Sustainable Happiness Model. In A. Dutt (Ed.), Happiness, Economics, and Politics: Towards a Multi-Disciplinary Approach (pp. 324-342). Cheltenham, UK: Edward Elgar Pub.

Simpson, J. A., \& Rholes, S. W. (2004). Anxious Attachment and Depressive Symptoms: An Interpersonal Perspective. In S. W. Rholes, \& J. A. Simpson (Eds.), Adult Attachment: Theory, Research, and Clinical Implications (pp. 408-437). New York: Guilford.

Spies Shapiro, L. A., \& Margolin, G. (2014). Growing up Wired: Social Networking Sites and Adolescent Psychosocial Development. Clinical Child and Family Psychology Review, 17, 1-18. https://doi.org/10.1007/s10567-013-0135-1

Strodl, E., \& Noller, P. (2003). The Relationship of Adult Attachment Dimensions to Depression and Agoraphobia. Personal Relationships, 10, 171-186. https://doi.org/10.1111/1475-6811.00044

Suh, A. (2013). The Influence of Self-Discrepancy between the Virtual and Real Selves in Virtual Communities. Computers in Human Behavior, 29, 246-256.

https://doi.org/10.1016/j.chb.2012.09.001

Tellegen, A. (1982). Brief Manual for the Differential Personality Questionnaire. Minneapolis, MN: University of Minnesota Press.

Turel, O., \& Serenko, A. (2012). The Benefits and Dangers of Enjoyment with Social Networking Websites. European Journal of Information Systems, 21, 512-528. https://doi.org/10.1057/ejis.2012.1

Turel, O., He, Q., Xue, G., Xiao, L., \& Bechara, A. (2014). Examination of Neural Systems Sub-Serving Facebook “Addiction”. Psychological Reports, 115, 675-695.

https://doi.org/10.2466/18.PR0.115c31z8

Veenhoven, R. (1996). Happy Life-Expectancy. Social Indicators Research, 39, 1-58. https://doi.org/10.1007/BF00300831

Veenhoven, R. (2008). Healthy Happiness: Effects of Happiness on Physical Health and the Consequences for Preventive Health Care. Journal of Happiness Studies, 9, 449-469. https://doi.org/10.1007/s10902-006-9042-1

Walther, J. B. (2007). Selective Self-Presentation in Computer-Mediated Communication: Hyperpersonal Dimensions of Technology, Language, and Cognition. Computers in Human Behavior, 23, 2538-2557. https://doi.org/10.1016/j.chb.2006.05.002 
Yee, N., Bailenson, J. N., \& Ducheneaut, N. (2009). The Proteus Effect: Implications of Transformed Digital Self-Representation on Online and Offline Behavior. Communication Research, 36, 285-312. https://doi.org/10.1177/0093650208330254

Zhao, S., Grasmuck, S., \& Martin, J. (2008). Identity Construction on Facebook: Digital Empowerment in Anchored Relationships. Computers in Human Behavior, 24, 18161836. https://doi.org/10.1016/j.chb.2008.02.012 